\title{
Elliot Rapaport MD, FACC 22 Nov 1924- 05 sept 2010: un tributo \\ Edgardo Escobar
}

\section{Señor Editor:}

Ha dejado de existir el Profesor Elliot Rapaport, por muchos años Jefe de Cardiología del San Francisco General Hospital, California, USA.

Escribo estas palabras con un gran pesar porque el Dr. Rapaport fue mi mentor durante los dos años en que fui becado en el Cardiovascular Research Institute de la Universidad de California, en San Francisco.

Hombre de una inteligencia extraordinaria, de gran dedicación a la investigación, la docencia y el cuidado de los enfermos. Nunca abandonó su asistencia al hospital hasta pocos días antes de su muerte.

Fue para muchos, entre ellos el suscrito, y posteriormente los Drs. Gastón Chamorro y José Antonio Rodríguez , un estímulo permanente para la investigación y la medicina académica, amalgamando en una forma excepcional los conocimientos de ciencias básicas y la práctica clínica, ejemplo que he tratado siempre de trasmitir a mis alumnos.

Con grandes dotes matemáticas construyó su propio computador desde un teclado y procesador de su madre, "sólo para ver si podía hacerlo". Fue, además, un gran violinista, tocando a los 12 años con la Orquesta Filarmónica de Los Ángeles, pero luego decidió seguir los pasos de su padre y se dedicó a la Medicina, de lo que "nunca se arrepintió".

Ocupó los más altos cargos académicos en su Facultad y también los de las Sociedades Científicas, llegando a ser Presidente de la American Herat Association y de la World Heart Federation. Fue, además, Editor de Circulation y dio conferencias en muchos países del mundo, siendo honrado con las más altas distinciones.

Elliot Rapaport fue un hombre excepcional y merece el agradecimiento de la Sociedad Chilena de Cardiología, porque además de lo ya mencionado, estuvo en Chile en cuatro oportunidades. La primera se prolongó por un mes, realizando experimentos en el Hospital Salvador, Universidad Católica, J.J Aguirre y visitando varios centros del país, algo absolutamente inédito hasta el día de hoy. La última vez fue el año 1995 cuando organizamos el Congreso Interamericano de Cardiología, en que vino sólo por un día para dictar la Conferencia Plenaria de la World Heart Federation, haciendo un gran esfuerzo. Con justa razón es miembro honorario de nuestra Sociedad.
Correspondencia:

Dr. Edgardo Escobar FACC, FAHA

Profesor de Medicina

Editor Asociado, Circulation

Email: e.escobar@itms.cl 